\title{
Heidegger y Trakl: el paraje occidental y el viaje poético ${ }^{1}$
}

\section{Heidegger and Trakl: occidental place and poetical travel}

\section{FRANÇOISE DASTUR}

Heidegger ha consagrado, desde los años treinta, numerosos textos a la pregunta de la «vecindad» entre poesía y pensamiento, y esta reflexión se ha concentrado primero en ese poeta de la poesía que es, a sus ojos, Hölderlin. Y es cierto que Hölderlin es el poeta por excelencia para Heidegger, quien lo ha leído muy pronto, desde sus años de estudio. Pero en la misma época, igualmente, ya había leído a tres poetas diferentes que fueron objeto más tarde de sus «comentarios», de sus Erläuterungen: Rainer Maria Rilke, aunque lo considere como un poeta que permanece adherido a la metafísica, al cual consagró en 1946 un texto magnífico, «¿Para qué poetas en tiempos de miseria2?»; Stefan George, poeta que fue muy admirado al final del siglo XIX y a principios del XX, y que reunió alrededor de él un gran número de escritores, de poetas y de pensadores en el marco del George-Kreis, del círculo Stefan George, en el que se interesó el joven Heidegger; y, en fin, Georg Trakl, quien nació y vivió en Austria y quien es, posiblemente, después de Hölderlin, el poeta al que Heidegger se siente más próximo, al que confiesa la más grande admiración. Aunque Heidegger le haya descubierto desde la primera publicación de sus poemas en 1919, cinco años después de su muerte, sin embargo, le consagrará solo dos textos, muchos años después; el primero retoma el texto de una conferencia dada en 1950, el segundo fue publicado en 1953. Estos dos textos serán reunidos en 1959 en el volumen intitulado Unterwegs zur Sprache, Camino al $h a b l a^{3}$, el mismo dedicado a otro poeta vivo, el francés René Char, del que Heidegger había tenido conocimiento algunos años antes.

\footnotetext{
${ }^{1}$ Este texto ha sido publicado en: Noesis $n^{\circ}$ 7, marzo del 2004, Paris, Vrin, pp. 19-41, el cual puede consultarse en línea en http://noesis.revues.org/22. El texto se ha presentado primeramente como una conferencia, lo cual puede verse en el estilo y los incisos mismos del escrito. Agradezco a Françoise Dastur por su buena disposición al momento de acoger esta traducción. [N. de T.]

2 Cf. Martin Heidegger, Chemin qui ne mènent nulle part, Paris, Gallimard, 1962, p. 323-385.

${ }^{3}$ Martin Heidegger, Acheminement vers la parole, traducido por Jean Beaufret, Wolfgang Bromeier y François Fédier, Paris, Gallimard, 1976.
} 
La lectura que Heidegger nos da aquí de la poesía de Trakl ha levantado las mismas críticas que anteriormente provocó con la de Hölderlin: se le ha acusado en los dos casos de haber procedido a una interpretación arbitraria y de haber querido, forzosamente, ver en ellos dos portavoces de su propia visión de la historia y de la modernidad. Todos los estudios consagrados a Trakl a partir de los años cincuenta, y son numerosos, se han esforzado por distanciarse, muchas veces violentamente, de la interpretación heideggeriana. Esta tiene posiblemente por qué indignar a los filólogos y a los historiadores, aquellos que quieren mantener desde allí una investigación de la lengua completamente singular de Trakl, o que desean volverle a atar al expresionismo alemán. Sin embargo, queda por preguntarse si esas últimas aproximaciones vienen siempre a dar cuenta de lo que, en los enigmáticos poemas de Trakl, no se deja simplemente conducir al destino de un ser singular o incluso de una generación, pero concierne a la situación misma del hombre en tanto que ser histórico. Es en ese nivel que se impone la interpretación que Heidegger nos da del «paraje» de Trakl. De los dos textos que Heidegger ha consagrado a Trakl, el primero, intitulado «El habla» (Die Sprache), consiste en un comentario a un solo poema de Trakl, Ein Winterabend, «Una tarde de invierno», mientras que el segundo, «El habla en el elemento del poema» (Die Sprache im Gedicht) es, como lo señala el subtítulo, una verdadera «situación» del ensamble de los poemas de Trakl, en la cual cita o menciona más de una cuarentena de poemas de la centena que nos ha dejado Trakl. La interpretación de Heidegger designa incluso expresamente el paraje de su poesía por el término, que toma prestado de Trakl, de Abgeschiedenheit, el cual tiene el sentido alemán corriente de «retiro», «aislamiento», estado del que está separado o ha fenecido (abgeschieden) y que se ha despedido (Abschied): es alrededor de ese término - el cual, según Heidegger, indica la profunda comprensión de la historia de Occidente que tenía Trakl- que gira todo el comentario que nos revela de su poesía.

La conferencia «Die Sprache im Gedicht» comporta, en efecto, el siguiente subtítulo: «Eine Erörterung von Georg Trakl Gedicht», que Beaufret, quien ha traducido esta conferencia hacia $1958^{4}$, vierte por «Situación del dict 5 de Georg Trakl»6. Dejo de lado, por el momento, la palabra Gedicht, para concentrarme en la palabra

\footnotetext{
4 Cf. La Nouvelle Revue Française, enero y febrero de 1958, n 61, p. 52-75, et n 62, p. 213-236.

5 Esta palabra, que conservamos en francés, es un neologismo de Beaufret para la traducción de la palabra alemana Gedicht, que quiere decir "poema" o "poesía". Según el Larousse dict es, para Heidegger, la palabra poética, en oposición al enunciado científico o filosófico; además podría venir del latín dictum, dit. Este neologismo puede tener relación con dit (dicho), participio de dire (decir). El traductor al español del texto de Heidegger traduce Gedicht por "Poema". Dejamos la palabra francesa tal cual, no sólo por la dificultad de traducir un neologismo, sino por tratarse de una traducción al francés del alemán que comentará la autora. [N. de T.]

${ }^{6} \mathrm{La}$ traducción al español este subtítulo dice: "Una dilucidación de la poesía de Georg Trakl". Heidegger, De camino al habla (tr. Yves Zimmerman), España: Odós, 1990, p. 33. [N. de T.]
} 
Erörterung, situación. Esta palabra significa en alemán corriente «discusión», «debate», pero Heidegger quiere aquí darle su sentido etimológico, pues esta palabra está construida por Ort, que significa lugar o paraje. Se trata pues, para él, menos de comprometerse en un análisis exhaustivo de la poesía de Trakl que de indicar su paraje. Pero ¿qué es el paraje de un decir poético, si no se entiende esta pregunta de manera historiográfica, es decir, en relación con la época, con el país y con la lengua; ni de manera biográfica, es decir, por referencia a la historia personal de su autor; ni de manera sicoanalítica, es decir, en referencia no al siquismo consciente, sino al inconsciente y a los fantasmas del autor; y si, en fin, no se entiende más de manera sociológica, es decir, como relativa a un medio social dado? Historia, biografía, sicoanálisis, sociología, hemos reconocido allí los marcos interpretativos fundamentales de las obras de arte que tienen curso hoy, y si Heidegger cita aquí el sicoanálisis, él que no habla de eso prácticamente nunca, es precisamente porque este ha sido frecuentemente invocado para dar cuenta de las relaciones que Trakl mantuvo con su hermana Grete. Uno de sus poemas es intitulado «Incesto», en alemán «Blutschuld», literalmente «culpa de sangre», pero nada permite concluir que algo de eso ha tenido lugar verdaderamente; e incluso si ese fue el caso, ciertamente eso no basta para explicar esta voluntad de autodestrucción que animó también al hermano, quien se vuelve farmacéutico para poder drogarse, como a la hermana, quien se suicidó a los veinticinco años, tres años después de su hermano, quien muere de una «sobredosis» de cocaína a los veintisiete años. No se trata, pues, para Heidegger, de referirse a alguno de esos marcos interpretativos externos a la obra para comprender esta, sino de encontrar, al contrario, en la obra misma el principio de su comprensión. Por eso hace la alusión al sentido etimológico de la palabra «Ort», paraje, que no significa el lugar en el sentido general, sino que designa originalmente la punta de lanza donde se ensambla todo el poder del arma, es decir, aquí el punto de convergencia, de ensamblaje ${ }^{7}$, el punto supremo y extremo de la obra. Cuestionar en dirección del paraje del decir poético de Trakl es, pues, buscar no un lugar delimitado y estático, un punto que se vuelve a encerrar en sí mismo como en una cápsula la quintaesencia de la obra, sino, al contrario, un punto dinámico, la fuente a partir de la cual se prodiga la onda moviente de la multiplicidad de los poemas. Es precisamente porque tal paraje es la fuente de la obra que sigue estando allí el origen velado. Y es este origen de los múltiples poemas que Heidegger llama «Gedicht», una palabra utilizada en alemán para designar un poema singular, pero que también tiene, a causa de la partícula ge-, el sentido del

\footnotetext{
${ }^{7}$ En todo el texto se utilizan dos términos de difícil traducción por su estrecha relación, estos son rassemblement y ensamble, ambos hacen referencia a una unificación, una reunión de diferentes elementos. Para mantener la relación que hay en francés se traduce rassemblement por ensamblaje y ensamble por ensamble. Como verbo aparece en el texto solamente rassembler, que se traduce aquí por ensamblar [N. de T.]
} 
ensamblaje del ensamble [rassemblement de l'ensamble] de lo que es obra poética. Se comprende mejor, a partir de ahí, la frase de Heidegger que dice que «Jeder grosse Dichter dichtet nur aus einem einzigen Gedicht» y que Beaufret traduce como sigue: «Todo gran poeta no es poeta más que a partir de lo dictado por un Dict único ${ }^{8} \gg 9$, del todo de un Gedicht que permanece él mismo informulado, pero del cual cada poema singular proviene. En efecto, sin fuente única, sin paraje uno, no hay, para Heidegger, «gran» poesía.

La grandeza, precisa, se mide en la amplitud de la confianza que el poeta tiene en la unicidad de la fuente de su decir poético. Esta fuente, lo señalamos de nuevo, permanece fuera del habla, y lo que constituye el punto de convergencia de los poemas singulares del gran poeta es más bien del orden de la experiencia que del orden del decir. Un poco más lejos, Heidegger hablará del tono fundamental de la poesía de Trakl que da su unisón ${ }^{10}$ en el ensamble de sus poemas, y así sugiere que la unidad de la que habla es la de una tonalidad, de una Stimmung y de una Stimme, de una tonalidad afectiva y de una voz. Pero lo que es aquí remarcable es que, esta unidad de experiencia que está en el fundamento del ensamble de los poemas del gran poeta, Heidegger la piensa menos en relación al tiempo que en relación al lugar. Luego, sugiere, es en la representación metafísica y estética que el movimiento que va, en el poema, de la fuente no dicha al decir poético aparece primero como ritmo. Hace falta, en efecto, para Heidegger, pensar más profundamente la esencia del ritmo, no confundirla con los simples efectos sensibles del lenguaje poético. Como lo señala en otra conferencia del mismo volumen ${ }^{11}$, la significación original del griego rhusmos no es circulación y flujo, como se cree generalmente, sino ajuntamiento (Fügung). El ritmo no está, pues, referido a la circulación del devenir, sino, más bien, a la inmovilidad del lugar, pues es lo que hace concordar al movimiento poético, a esta onda que brota de la fuente y vuelve allí, a ese movimiento de flujo y de reflujo su estabilidad y sus límites. Por esto Heidegger declara que el ritmo es lo que da el reposo al movimiento de la música y de la danza, y la ajunta en un todo armonioso al dejarle reposar en sí.

Es, pues, lo que hay de inmóvil en la poesía, lo que constituye eso que podríamos llamar su arquitectura oculta, que trata de hacerse manifiesto en lo que Heidegger llama Erörterung, situación. Se trata, explica, de remontarse, a partir de

\footnotetext{
8 Cf. M. Heidegger, Unterwegs zur Sprache, Neske, Pfullingen, 1959, p. 37 ; traducción, op. cit., p. 41-42.

${ }^{9}$ La traducción al español de esta sentencia de Heidegger dice: "Todo gran poeta poetiza sólo desde un único Poema”. Heidegger, De camino al habla (tr. Yves Zimmerman), España: Odós, 1990, p. 35. [N. de T.]

10 Traduzco unisson por unisón, teniendo en cuenta la literalidad, pero haciendo la salvedad de que la palabra francesa es un sustantivo y que tiene, además del sentido musical, el sentido figurativo de "acuerdo de pensamientos, de sentimientos o entre personas". [N. de T.]

11 Ibid., p. 230, traducción, p. 215.
} 
los poemas singulares, al paraje del que provienen, y este remontarse es, pues, un viaje que nos hace pasar de lo dicho a lo no-dicho, de la onda a su fuente. Pero, para entender la unidad del tono fundamental de la poesía de Trakl, hace falta partir de los poemas aislados y de su elucidación. Hace falta, pues, comenzar por lo que Heidegger llama Erläuterung, aclaración, por la cual la voz que habla en el poema puede ser entendida (notamos aquí que la palabra laut, lauter remite en alemán tanto a la sonoridad de la voz como a la claridad de lo que es límpido y brilla por sí mismo). En la lengua corriente, Erläuterung tiene el sentido de comentario y designa el ejercicio escolar de la explicación de texto. Lo que es claro (das Lautere) es llevado por eso a su primer aparecer. La aclaración hace ver o hace oír lo que es dicho en el poema singular. Pero una buena elucidación presupone ya la situación, pues no es más que a partir de la fuente de la poesía que los poemas singulares brillan y resuenan. E, inversamente, la situación necesita, para acceder al lugar, para hacer oír el tono fundamental que atraviesa todos los poemas, que estos sean de antemano recorridos y elucidados. Heidegger no habla aquí del círculo, sino de una relación de reciprocidad (Wechselbezug), de un intercambio entre Erläuterung y Erörterung, entre aclaración y situación. No queda menos, que es de lo que se trata aquí, de lo que ha llamado en Ser y tiempo círculo de la comprensión12. La situación hermenéutica y su puesta en marcha, necesariamente circular, eran ya puestas en evidencia en 1927, y Heidegger anotaba, a propósito de esto, que no se trataba de condenar el círculo, de ver en él una falta lógica, sino, al contrario, de entrar en este, pues pertenece a la estructura misma del sentido que exige que la comprensión se preceda, por así decir, a ella misma y que toda explicitación parcial sea guiada por una intención anticipada del todo que no es ella misma posible más que por el análisis de la parte.

Heidegger sugiere así que todo diálogo pensante con la poesía de un poeta sigue preso en ese "círculo hermenéutico», donde situación y aclaración se presuponen recíprocamente el uno y el otro. El término de Zwiesprache, al cual él ha recurrido entonces, indica aquí la situación de una palabra intercambiada entre dos compañeros, y Heidegger señala que el verdadero «diálogo» con la poesía es el de los poetas entre ellos, lo que implica que, en ese caso, la palabra intercambiada es en ambos sentidos poética. Pero un diálogo diferente es también posible y, a veces, incluso necesario; es el diálogo del pensamiento y de la poesía, pues cada uno de los dos tiene una relación insigne con la palabra. Heidegger encuentra aquí una idea que ya ha expuesto muchas veces desde los años treinta, y antes en sus primeras «aclaraciones» a la poesía de Hölderlin: pensamiento y poesía no se limitan a utilizar las palabras, no tienen una relación instrumental con el lenguaje, pero se despliegan cada uno de las dos en el elemento mismo de la palabra, lo que implica que

12 Cf. Martin Heidegger, Etre et temps, Paris, Gallimard, 1986, § 32, p. 198 [153] ss. 
en ellos el «sentido» no sea desatable de su soporte lenguájico13. Esta relación insigne con la lengua, aunque sea diferente en los dos casos y que no permite, pues, identificar poesía y pensamiento, sino más bien hablar de su «vecindad», es una relación de habitación, un ser que permanece en la palabra que caracteriza el estatus de aquellos que Heidegger no llama los hombres, sino los mortales, aquellos, dice, en una conferencia fechada en la misma época, que son «capaces de la muerte ${ }^{14} \gg$. Mortal no es, pues, el nombre de un ser provisto de determinaciones negativas, como es tradicionalmente el caso, sino, al contrario, una denominación que implica una «capacidad»: la capacidad de no erigirse como sujeto de representación, de no constituirse como «punto de Arquímedes», para retomar una expresión cartesiana, sino de pensarse, al contrario, como «al servicio» del aparecer, como «empleado» (gebraucht) por el ser, y como su compañero en el diálogo mantenido con él. El mortal es el que responde al llamado del ser y que no está, pues, en posición primera, lo que implica que su palabra no es su dócil instrumento, una técnica que se habría dado él mismo para dominar los fenómenos, sino, al contrario, un don que recibe y por cuyo uso tiene que responder. El pensador y el poeta hacen, el uno y el otro, la prueba de este «ser» de la palabra, y aquí la palabra Wesen tiene el sentido que le da Heidegger ya desde los años cuarenta, a saber, el sentido del antiguo verbo del alto alemán wesan, que significa «desplegar su ser», antes que el tradicional de «esencia», que supone la distinción, ella misma tradicional, de la esencia y la existencia, y el khorismos, heredado del platonismo, separando lo sensible de lo inteligible.

Lo que hace, pues, necesario el diálogo entre poesía y pensamiento es, precisamente, el hecho de que nos encontramos hoy conminados a llamar allí al despliegue del ser de la palabra a fin de que esta devenga en nueva, porque ella ya es la permanencia del ser, también del hombre. Se trata, en efecto, como lo decía ya Heidegger en su conferencia sobre «La cosa», para los hombres de «devenir mortales $15_{\text {» }}$ y abandonar así su estatus de sujeto, lo que implica, como lo dice aquí, que ellos aprendan a habitar en la palabra. Es en tal aprendizaje que puede llevar el diálogo entre pensamiento y poesía, diálogo del cual Heidegger señala que apenas ha comenzado y que requiere, sobre todo en lo que concierne al poeta que es Trakl, una retención completamente particular. Pues un diálogo tal esconde un peligro, el de perturbar el decir poético antes que dejarle ser tal cual es, a saber, un canto, un encantamiento de las cosas y no simplemente su designación. En sus Erläuterungen

\footnotetext{
13 La palabra que utiliza aquí la autora es langagier, palabra que se refiere al lenguaje, pero que, en el caso en que la usa Heidegger no se refiere a este en el sentido lingüístico, sino al lenguaje en cuanto a su relación con el ser. El neologismo lenguájico ya ha sido usado por otros traductores e intérpretes de Heidegger. [N. de T.]

14 Cf. Martin Heidegger, «La chose » (1950) in Essais et conférences, Paris, Gallimard, 1954, p. 212.

15 Cf. Essais et conférences, op. cit., p. 213.
} 
zu Hölderlins Dichtung, publicadas también al principio de los años cincuenta, Heidegger evocaba el riesgo al que se enfrenta toda aclaración de los poemas, el riesgo de hacer violencia a lo poético y de someterle al yugo del concepto. Por eso determinaba como el último paso por completar para la aclaración su propia borradura ante «la pura presencia del poema», a fin de que ante esta alcance a volverse ella mismo inútil16. La aclaración debe, pues, aspirar a volverse superflua y no interponerse entre el poema y nosotros. Asimismo, aquí la situación de la poesía nunca puede sustituirse en el poema, no puede remplazar la escucha, y ni siquiera guiarla. Pues ella no puede usar ninguna herramienta externa como explicación, no puede ni partir de la visión del mundo del poeta, ni del inventario minucioso de sus herramientas poéticas. No puede, en el mejor de los casos, más que volver nuestra escucha más problemática, más digna de cuestión y más meditante. No se trata, pues, de proceder a una aproximación analítica de la poesía de Trakl, sino de ponerse en busca de la localidad del lugar del poema, de la región donde se despliega, búsqueda de la cual hace falta señalar de nuevo el carácter arriesgado: el mismo Heidegger reconoce que ella aparece como una búsqueda bien limitada, que no hace uso de todas las informaciones de las que disponemos sobre la poesía de Trakl, y que parece, incluso, constituir una aberración a los ojos de todos aquellos que hoy consideran que el análisis es el procedimiento de aproximación, el único válido de las producciones culturales.

Heidegger reconoce, pues, que su manera de proceder en la situación que emprende de la poesía de Trakl puede parecer arbitraria, ya que debe apoyarse en un cierto número de versos sacados de los poemas de Trakl, pero esta apariencia de arbitrario proviene del salto (Heidegger dice más precisamente Blicksprung, salto de la mirada) que es necesario para hacernos pasar de lo dicho a lo no dicho. Ahora bien, este salto nos conduce a un verso sacado del poema intitulado «Primavera del alma» (Frühling der Seele), del cual Heidegger no citará los nueve últimos versos más que al final de la conferencia. Este verso dice: «Es ist die Seele ein fremdes auf Erden» «El alma es en verdad algo extraño en la tierra», y forma el hilo conductor de la primera parte de la conferencia. Heidegger comienza por señalar que este verso puede ser comprendido a partir de la representación platónica de la oposición entre lo sensible y lo inteligible, la tierra por una parte, dominio de lo perecedero, y el alma por otra parte, dominio de lo imperecedero. La extrañeza del alma vendría, así, de su no-pertenencia a lo sensible, del hecho de que ella no es de la especie (Schlag) terrestre y que ella es, pues, desplazada (verschlagen) en la tierra. Pero Heidegger, quien quiere sustraer a Trakl de ese platonismo tradicional, se dedica a mostrar que la palabra «fremd», que se traduce habitualmente por «extraño» 17 , sig-

\footnotetext{
16 M. Heidegger, Approche de Hölderlin, Paris, Gallimard, 1973, p. 8.

17 La palabra que se traduce por extraño es étranger, en algunos casos puede tener el sentido de alguien que es extraño en otra región, en ese caso podría traducirse por extranjero, y otras veces tiene
} 
nifica en realidad, en antiguo alemán, pues, en la lengua medieval, donde tiene la forma «fram», en camino hacia, tendiendo hacia un lugar diferente. Lo que es extraño es, pues, literalmente, lo que viaja, no lo que yerra sin meta, sino lo que avanza así hacia el lugar que le es apropiado. A partir de ahí, el verso citado toma un sentido diferente: el alma no huye de la tierra, lugar inhabitable para ella, como lo quiere el platonismo tradicional, sino, al contrario, busca la tierra. Hace falta, pues, oír este verso de diferente modo: la extrañeza en la tierra no es el atributo del alma, sino, en la medida en que llama a su ser en camino hacia la tierra, su esencia misma. Su extrañeza no es, en efecto, nada diferente que su ser en camino, lo que la define como tal, la esencia del alma siendo precisamente ser en peregrinación, en movimiento hacia. Pero ¿hacia qué? Aquí Heidegger debe hacer un llamado a otro verso de otro poema para precisarlo, «Sebastian im Traum», «Sueño de Sebastian», donde es cuestión de un pájaro, de un tordo que llama al declinio a algo extraño. Pero ese declinio no es precisamente el hecho para el alma de abandonar la morada terrestre, y ese declinio no es ni decadencia ni catástrofe según Heidegger, quien cita, para apoyarse, un verso de un tercer poema, «Otoño transfigurado» (Verklärter Herbst), que asocia el declinio al reposo y al silencio. Se trata, en efecto, para Heidegger, de pensar de manera no negativa el declinio. Por eso cita de nuevo «Primavera del alma», donde aparece el verbo «dämmern» que es empleado tanto para la salida del día como para la caída de la noche; la Dämmerung designando en alemán sea el alba sea el crepúsculo, y no significando pues, necesariamente, el declinio. El verso citado dice precisamente: Geistlich dämmert/Bläue über den Verhauenen Wald: «espiritual el azur ${ }^{18}$ dämmert (se eleva o cae) sobre el bosque abatido». Aquí una nueva relación se revela, la de lo que es Geistlich, «espiritual», en ese momento de claro-oscuro que precede el salir o el caer del sol, y que es un momento de inclinación del astro, de esta declinación en el sentido general del sol de la cual habla el poema intitulado «Sommersneige», «Declinio del verano», que dice de esta declinación que es «leise», «discreta», que adviene sin ruido, suavemente; es decir, precisa Heidegger, quien de nuevo ha recurrido a la etimología de esa palabra, «lentamente», por deslizamiento. Es en este mismo poema que es cuestión del «Fremdling», del extraño caminante con pasos sonoros en la noche plateada y de un azul buscado ${ }^{19}$ que debe guardar memoria de su sendero y de los acordes armoniosos de sus años espirituales.

el sentido de algo indeterminado. Debe tenerse esto en cuenta ya que algunas veces puede referirse a alguien o a algo, aunque ha sido siempre traducida por extraño, para mantener la palabra y no desorientar la lectura. [N. de T.]

18 La palabra azur en francés tiene otras acepciones, a diferencia de la definición de la palabra en castellano. Puede significar "el cielo o el aire" o "color de un azul intenso". Esta palabra parece ser empleada especialmente en la poesía, lo cual dificulta su traducción por su contenido abstracto. [N. de T.]. 19 El término utilizado aquí, el cual siempre está acompañado de "azul" es gibier, sustantivo masculino que puede significar "venado" o "conjunto de animales de caza". Sin embargo, también tiene el sentido de "lo que se persigue o de lo que uno hace su alimento intelectual". Este último sentido, que 
No es posible aquí seguir con detalle todas las relaciones que opera Heidegger entre algunos versos de poemas diferentes. Basta quizá señalar que Heidegger intenta delimitar, por esas citas, el significado del azur para Trakl, de ese azul o de esa azuleidad de la cual ya hablaba Hölderlin en uno de sus últimos poemas, «En azuleidad adorable», y que representaba para Novalis, poeta admirado por Trakl, el color del ideal en su Heinrich von Ofterdingen. Uno de los versos citados por Heidegger, con el tema del azur, lo caracteriza como «heilig», santo o sagrado, y es necesario recordar que este término en la obra de Hölderlin no debe ser comprendido en su sentido corriente, como lo que se opone a lo profano y como constituyente, por eso, de una región diferente a la mundana, sino en su sentido literal, que significa lo indemne, lo intacto, lo no cortado; el verbo heilen, que quiere decir sanar, perteneciente a la misma familia que el inglés whole, entero. Se comprende mejor, a partir de ahí, que Heidegger pueda afirmar que el azur no es una imagen de lo sagrado, sino lo sagrado mismo en tanto que es profundidad reuniente, potencia de ensamblaje. Hay pues una relación entre el azur, lo espiritual y lo sagrado. El azul buscado, del cual es cuestión en el poema y al cual el poeta ordena no olvidar el sendero de lo extraño, es, pues, un raro animal, ya que debe acordarse y mirarse un animal aún por venir, ese animal rationale del que Nietzsche decía que no estaba aún fijado, aún establecido en su propia esencia ${ }^{20}$. El establecimiento, la definición sentenciada de tal animal, que reúne en él lo sensible y lo inteligible, es el objeto de los esfuerzos de la metafísica occidental desde Platón, y Heidegger, quien ha buscado en Ser y tiempo dar una definición completamente diferente del hombre, no titubea en sugerir que esos esfuerzos son quizá vanos, pues las premisas de las que parte, a saber, la dualidad interna del hombre, no le abre ninguna vía practicable. Este animal aún no detenido en su ser, porque es doble, es el hombre de ahora. Cuando el azul buscado es ese mortal que se acuerda de lo extraño, luego del alma y de su marcha, y que querría viajar con él hasta huir de la esencia humana. Aquellos que acompañan así lo extraño en su viaje son los pocos, los desconocidos, «si es verdad, añade Heidegger, que lo esencial adviene furtivamente, en lo improvisto, y como la excepción ${ }^{21_{\gg}}$. No se puede aquí más que ver una reminiscencia de ese pasaje del Zaratustra de Nietzsche, intitulado "La hora más silenciosa», donde es dicho que «son los pensamientos, los que vienen como llevados en patas de palomas, quienes dirigen el mundo 22 》. Esta puesta en relación, por Heidegger, de la poesía de Trakl con el pensamiento de Nietzsche parecerá menos arbitraria si se recuerda que Trakl mismo ha sido un lector y un admirador apasionado de Nietzsche.

está en estrecha conexión con la caza, no se puede perder de vista. He traducido, a falta de una mejor opción, esta palabra por "buscado" [N. de T.]

20 Ver en Qu'appelle-t-on penser? , Paris, PUF, 1959, p. 53 ss. El comentario que hace Heidegger de esta palabra de Nietzsche.

21 Acheminement vers la parole, op. cit., p. 49.

22 F. Nietzsche, Ainsi parlait Zarathoustra, Paris, Mercure de France, 1958, p. 152. 
Este azul buscado, cuando aparece, ha abandonado, pues, su apariencia humana, el hombre bajo su forma tradicional de animal rationale, así ha entrado en decadencia, se deshace, pierde su esencia, verwest. El hombre antiguo ha muerto, no en el sentido en que ha abandonado la vida terrestre, sino en el sentido en que ha abandonado su antigua esencia, en que ha entrado en este declinio que no es absolutamente negativo, al cual lo extraño se ve llamado. Esta muerte no es, pues, descomposición, sino, al contrario, el abandono de la forma descompuesta del hombre. Hace falta, para comprender aquí lo que sugiere Heidegger, acordarse de la distinción que hace Nietzsche, al comienzo de su Zaratustra, entre el último hombre y el superhombre. El último hombre es el hombre moderno, quien no pone más estrellas en el mundo 23 , y quien, no alcanzando a realizar su esencia, es este hombre en la forma descompuesta de la que habla Trakl. El superhombre es el hombre que quiere reintegrar su verdadera esencia, que se sobrepone, pues, a la descomposición y que abandona la forma que el hombre ha revestido hasta aquí. La especie de la forma descompuesta del hombre, de la que habla Trakl, es la especie arrancada de su modo de ser y, así, deportada o depuesta (entsetzt) fuera de su esencia.

Es a partir de ahí que el texto de Heidegger se vuelve enigmático. Él pregunta: ¿con qué es golpeada esta especie, es decir, maldita (verflucht)? La traducción de Beaufret evita aquí la palabra «maldición» y «maldecir» por Fluch y Verfluch, palabras con connotación cristiana que emplea Trakl, posiblemente porque Heidegger indica que este término conduce al griego plègè, que Beaufret traduce por «plaga». Veremos que Heidegger mismo plantea, un poco más lejos en la conferencia, la cuestión del cristianismo de Trakl. Por el momento, lo que importa es comprender en qué consiste la maldición de la especie en descomposición. Es, explica Heidegger, que esta antigua especie es golpeada hasta el desgarramiento por la discordia (Zwietracht) de las especies. Hay, pues, una tensión (Tracht) entre las dos especies de las cuales Heidegger nos dice que ella conduce a cada especie a abalanzarse de manera desenfrenada en la simple salvajez de lo buscado y, así, a aislarse. Sin embargo, añade Heidegger, no es la dualidad misma de las especies la que es la maldición, sino su disensión o su discordia, lo que luego hace de la dualidad una guerra de las especies. La maldición es el aislamiento, la Vereinzelung de las especies, su separación en la guerra. Hay, pues, una buena y una mala manera de vivir la individuación, el devenir uno: el buen golpe es el que permite la aceptación de la dualidad de las especies en lo que ve en ambas la suavidad de un simple doble pliegue (einfältigen Zwiefalt), y está así atento a la extrañeza del desdoblamiento; es decir, según el sentido que Heidegger ha dado a extrañeza, a lo que calificaré, para simplificar su carácter, dinámico y no estático. No hay aquí referencia explícita a la dualidad de los sexos, aunque el término Geschlecht pueda conducir indiferentemente a la especie o al sexo, y que se pueda, desde luego, pensar en la relación del

23 Ibid., p. 11. 
hermano y de la hermana, tan presente en la poesía de Trakl, y en el raro parecido físico que le unía a Grete; el tema es más bien el de la relación del individuo con los otros, con aquellos de los que se separa justamente lo extraño que gana lo amplio (auswandert); es decir, quien llega más lejos del aislamiento estático en una especie cerrada. Es precisamente porque vive la individuación de manera dinámica que, separándose de los demás, de aquellos que permanecen en la guerra de las especies, sigue siendo atacado por ellos por la veneración y el amor. El alma viajera de lo extraño se vuelve así «alma de azur» («blaue Seele»), un alma que se abre entonces a la unicidad de lo sagrado. No obstante, se separa, se despide de la especie en descomposición.

Es por eso que el extraño se vuelve el que está llamado a separarse de los otros, a partir de allí, el que se despide, der Ab-geschiedene. Vuelvo aquí sobre la traducción dada por Beaufret de esta palabra: partida, Dis-cédé24. Beaufret ha querido así ligar todas las connotaciones atribuidas a esta palabra: partida, alejamiento, fallecimiento. Pero ha borrado así la idea de separación y/o de elección que puede atribuirse también a esta palabra, y que Heidegger señala aquí al hablar del llamado a separarse, del llamado a declinar, a perderse en el claro-oscuro espiritual del azur. Se ve claramente aquí que el declinio no es en absoluto decadencia, sino, al contrario, entrada en el espíritu, el contrario mismo de lo que adviene al último hombre nietzscheano, que decae en la bajeza. Tal declino corta el peligro de la destrucción, debe pasar por el invierno -y aquí haría falta señalar la importancia de las estaciones para Trakl y, como lo anotaba más arriba Heidegger, comprender que el camino de lo extraño sigue el del sol, que le conduce a recorrer el año, cuyo nombre en indo-europeo ier es de la misma raíz que el ienai griego que significa caminar, al igual que del alemán Jahr (año) y gehen (caminar). Perderse no es, pues, idéntico a anonadarse, incluso si el riesgo de eso es también sabido: perderse -en lo sagrado, abandonar así la crispación en el aislamiento, la guerra de las especies-, es paradojalmente soltarse (los-lösen) y esa soltura de lo extraño le conduce a deslizarse lentamente, a desaparecer en tanto que individuo aislado en la destrucción invernal; no para esfumarse allí, sino para, pasando por ella, acceder al tardecer, al crepúsculo espiritual occidental. Eso es lo que Heidegger lee en una de las estrofas del largo poema Helian, que consuena con ese verso ya citado de «Alma de otoño» que dice: «La tarde cambia sentido e imagen» (Abend wechselt Sinn und Bild). Tal tarde es,

\footnotetext{
${ }^{24}$ La traducción que hace Zimmermann al español de la palabra alemana Ab-geschiedene es Retraído. Ab-geschiedene se puede traducir por a-islado -lo cual parece más adecuado-, pues la "a" resalta, en su separación, una doble acción (privativa y no-privativa). Heidegger recurre constantemente a esta forma de expresión. La palabra francesa es otro neologismo de Beaufret. Cédé tiene el sentido de cedido, como en español, en su acepción de "dar espacio". Hacia allí parece inclinarse la traducción de Beaufret, aunque entendiéndola como des-cedido, en su doble relación a partir del guion, el cual muestra los dos posibles sentidos de la palabra. [N. de T.]
} 
en efecto, el lugar de una transfiguración -otra palabra frecuentemente utilizada por Trakl (Verklärung), de connotación cristiana también, y que se opone diametralmente a la Verwesung, a la descomposición-.

Heidegger explica que la tarde tiene el poder de cambiar sentido e imagen porque ella también cambia, porque no está separada del día, no más que la fuente lo está de la onda que surge de esta, porque es simplemente el declinio del día, una inclinación hacia un nuevo comienzo, el del viaje del extraño, del que siempre está «en camino», según el título mismo del volumen en el cual Heidegger ha publicado su conferencia. La tarde, Occidente, es pues el lugar de un cambio que, al abrigar en él mismo la despedida dada en el reino precedente del día y del año, abre la vía de un salir diferente del astro y de un año diferente.

Porque el extraño abandona la disensión, el lugar en que se mantiene es el de un ensamblaje. El lugar en que se mantiene el extraño, el que está en camino, el que se despide, se le puede llamar, dice Heidegger, die Abgeschiedenheit, el estado del que se va, que se separa no en la violencia del rechazo, sino para responder al llamado espiritual. Según Heidegger, es de ese lugar que surge la poesía de Trakl como un único canto. Y la palabra aquí empleada es Gesang -que se encuentra también en la obra de Hölderlin, que significa más que la palabra corriente alemana para canto, Lied-, que aparece justo después en el texto, pues la partícula ge-remite a la idea de ensamblaje de todas las voces, lo que se puede proponer para traducir por plenocanto 25 .

Heidegger aborda entonces el problema de la relación de la separación (Abgeschiedenheit), de la partida y de la muerte, para señalar que esta muerte, de la que habla Trakl en sus poemas, no es la muerte en el sentido ordinario del término, sino otra manera de vivir. Él cita, para apoyarse, un verso del poema intitulado «Salmo»: «En su tumba el blanco mágico juega con sus serpientes», lo que indica el cambio que ha habido en el lugar y que permite entonces jugar con lo que es el peligro mismo, el animal venenoso. Este cambio también es comprendido como locura, ya que lo extraño es llamado el Wahnsinnige, en el poema, pero no se trata aquí de la enfermedad mental, de sicología o siquiatría, pues esta ausencia de sentido que caracteriza al «loco», según la etimología misma de wana, que significa «sin», indica simplemente su estado de separación, su diferencia con los demás. Él es mucho más sensato que los demás, desprovisto del sentido de los demás, lo que quiere decir que camina en una dirección diferente; la palabra para sentido en alemán, Sinn, remite a la raíz indo-europea sent y set, que quiere decir camino. Heidegger cita el poema «A un joven muerto», «An einen Frühverstorbenen», a aquel que ha muerto apenas sale de la infancia y que en la muerte ha vuelto a ser tomado por ella, y anota que Trakl asocia la paz a la infancia. Se encuentra aquí la

25 Esta es la traducción que da François Fédier en F. Hölderlin, Douze poèmes, Paris, Orphée, La Différence, 1989, p. 65. 
insistencia, señalada por Heidegger, de las palabras «sanft» y «still», indicando, ya como leise, esa calma, esa lentitud y esa paz que caracterizan la tonalidad fundamental de la poesía de Trakl, su llamado a la suavidad contra la violencia de la disensión y de la guerra. Pero ¿quién es, pues, ese joven muerto?

Se alcanza, con la figura de Elis y del niño, un momento esencial de la poesía de Trakl. Elis, al lado de Sebastian y de Helian, otras figuras de niño presentes en la obra de Trakl, es para Heidegger la encarnación misma de lo extraño, pero no del mismo Trakl -como tampoco, precisa, el Zaratustra de Nietzsche puede ser identificado con el mismo Nietzsche. Heidegger señala la similitud que hay entre Elis y Zaratustra en la manera no negativa en la que ellos comprenden el declinio y se comprometen con él. Elis es la figura de la infancia, de una infancia más antigua que la vieja especie en descomposición, más antigua, anota Heidegger, porque es más sinnender, más viajera, más serena, fuera de disensión. ¿Qué es, en efecto, el niño? Aquel en que la dualidad de los sexos no se ha vuelto aún disensión, aquel del que el alemán habla en neutro, y que abriga y reserva en sí el tierno doble pliegue de los sexos. Elis no se descompone, pero pierde su ser (entwest) en la precocidad que es suya, una precocidad de la que Heidegger dice que no ha llegado aún en el llevar, zum Tragen, y es necesario aquí entender esta palabra en el sentido del viejo alto alemán giberan, que quiere decir llevar un niño, niñear. Es precisamente, según Heidegger, ese no-niñeado que Trakl llama lo ingenerado 26 (der Ungeborene) en el poema intitulado "Clara primavera», «Heiterer Frühling». Lo ingenerado y lo extraño son lo mismo, lo que implica que el que se ha separado no ha fallecido, al contrario, de alguna manera aún no ha nacido. Ahora bien, esa precocidad o esa mañana en la cual lo extraño ha entrado al declinar es un tiempo completamente particular, el tiempo de los años espirituales. Se trata de un tiempo particular porque en él el fin de la especie descompuesta precede al principio de la especie ingenerada. La verdadera temporalidad, sugiere aquí Heidegger, no es lineal, como la metafísica se la representa desde Aristóteles, quien ha definido el tiempo como el número del movimiento. El verdadero tiempo es la venida de lo que ha sido, no del pasado, es decir, de lo querido de nuevo, sino el ensamblaje de lo que ha sido y que precede toda venida. Este tiempo verdadero, como ya Heidegger lo mostraba en Ser y tiempo, se caracteriza por el hecho de que en él porvenir y pasado están en una relación recíproca, están en co-pertenencia o en co-originareidad. Este tiempo, Trakl lo llama espiritual, «geistlich». La palabra geistlich, cuyo sentido original significa «lo que va en el sentido del espíritu», ha sido hoy en día restringida a su contraste con lo temporal y asociada al estado eclesiástico, el del pastor. Heidegger anota que Trakl evita el empleo de la palabra «geistig» que es, ella, en el uso

26 Traduzco "ingénéré" por "ingenerado" y no por ingénito, que podría ser una palabra adecuada, para mantener la relación que hay con la generación en su sentido verbal, en lugar del adjetivo, contenido en el francés. [N. de T.] 
corriente, no opuesta a lo temporal, sino a lo material y hace, así, pues, parte de la gran oposición metafísica de lo sensible y de lo inteligible 27 . Ahora bien, tal forma de ver es la de la especie en descomposición. Esa es la razón por la cual, explica Heidegger, el crepúsculo en el que entra lo extraño no puede en absoluto ser llamado geistig.

Pero ¿qué es entonces el espíritu si no es definido metafísicamente? Heidegger cita el último poema de Trak1, «Grodek», que habla de la «llama ardiente del espíritu» (heissen Flamme des Geistes), y señala que, contrariamente a la tradición, el espíritu es, en la obra de Trakl, asociado al fuego y no al aliento, pneuma o spiritus. El espíritu, en tanto que llama, es el fuera de sí, das Ausser-sich (es por la misma expresión que Heidegger definía la temporalidad en $\operatorname{Ser}$ y tiempo $^{28}$ ) y Heidegger invoca aquí de nuevo la etimología de la palabra Geist, cuyo sentido original es «ser levantado, transportado, puesto fuera de sí»». El espíritu, así definido, es el origen único del bien como del mal, de la suavidad como de la violencia. Heidegger, como ya lo hacía a continuación de Schelling29, rechaza aquí la tesis metafísica según la cual el mal proviene de lo sensible, al afirmar que el mal es espiritual, espiritual no por oposición a lo material (geistig), sino en tanto que mal proveniente del espíritu (geistlich), en tanto que en él hay insurrección del elemento extático que se dispersa fuera de la dimensión ensamblante de lo sagrado. El mal está, pues, ligado a la ausencia de ensamblaje sin el cual no es suavidad. El espíritu es, en efecto, lo que arroja lo extraño en el viaje y que se hace, así, don del alma. Pero de vuelta, para que haya ensamblaje, el alma debe hacerse guardiana de la llama del espíritu.

Aquí se abre una magnífica meditación sobre el dolor en la cual Heidegger, citando a Trakl, ve «la grandeza del alma», de un alma que, al separarse, se abre al espíritu. Todo lo que vive, en el sentido del alma, está en el dolor, así afirma Heidegger. Y más lejos cita un verso de Trakl que dice que «si dolorosamente bueno y verdadero es lo que vive» (So schmerzlich gut und wahrhaft ist, was lebt), el dolor se ve, entonces, asociado al bien y a la verdad. El dolor es, así, el don del ser en todo lo que es. Es por eso que Heidegger ve en él «el puro acuerdo en la sacralidad del azur» (die reine Entsprechung zur Heiligkeit der Bläue ${ }^{30}$ ). Heidegger, después de haber explicitado la naturaleza del dolor, cita de nuevo el último poema de Trakl, «Grodek», que evoca también «la llama ardiente del espíritu» que «nutre hoy en día un potente dolor». Este espíritu es el del joven muerto del que habla el poema que

\footnotetext{
27 Ver, a propósito de esto, la lectura que Derrida hace, en De l'esprit, Paris, Galilée, 1987, p. 137 ss., del texto de Heidegger que abre con estas palabras: «Esta Erörterung del Gedicht de Trakl es, me parece, uno de los textos más ricos: sutil, sobredeterminado, más intraducible que nunca. Y, por supuesto, de los más problemáticos.»

28 M. Heidegger, Etre et temps, op. cit., § 65, p. 389 [329].

29 Cf. M. Heidegger, Schelling, Paris, Gallimard, 1977 (Curso del semestre de verano de 1936), p. 182 ss.

30 Acheminement vers la parole, op. cit., p. 67.
} 
le es dedicado. Es por eso que Heidegger puede afirmar que la Abgeschiedenheit, la separación, se despliega como el espíritu puro, y en tanto que tal, ella es la que ensambla 31 . Estamos aquí frente a una paradoja, ya que es la separación la que ensambla, lo que implica, como lo señala Heidegger, que en la separación (Abgeschiedenheit) el espíritu del mal no es destruido ni dejado libre, es transmutado, y no puede serlo más que si el alma es grande, que si se abre al dolor de la separación y retorna, así, a la infancia, a la serenidad de una dualidad que no es disensión. La separación ensambla, puro oxímoron, y es por eso que tiene la naturaleza del paraje.

Heidegger plantea entonces la cuestión de la relación de este paraje con la poesía, cuestión problemática, ya que es la de la relación entre lo no-dicho y el decir. En otros términos, ¿cómo puede ser la separación el origen de un canto, de acordes armoniosos, como lo dice el poema «Declinio del verano»? ¿Cómo comprender la Abgeschiedenheit: como separación que divide o como elección que ensambla? Heidegger cita de nuevo el poema «A un joven muerto», en el cual aparece el rostro del amigo que está a la escucha de lo extraño y que le sigue, volviéndose así también él viajero y extraño. Heidegger señala que el canto de lo extraño suscita la atención de aquellos que escogen seguirle. Es así, añade, como se completa la esencia de la separación: no es el paraje de la poesía más que si ella es, a la vez, recogida de la serenidad de la infancia, caída de lo extraño y ensamblaje de aquellos que siguen lo extraño, pues es por su escucha solamente que el canto de lo extraño se vuelve audible y accede al decir poético. Luego, Heidegger lo afirma, el decir poético, el Dichten, es un volver a decir (nachsagen), un decir como respuesta, y después, primero y antes que todo, una escucha. Es por eso que el decir poético puede guardar el paraje de la poesía, el Gedicht, como lo que es esencialmente no-dicho. Tal canto no puede nacer más que de la noche, de la oscuridad que atraviesa lo extraño, pues esta noche, que llama tanto los poemas de Trakl, es una «noche espiritual», eine geistliche Nacht, una noche que no es en absoluto destrucción del espíritu, sino donde brilla la claridad de su ausencia. Ya, a propósito de Hölderlin, Heidegger había señalado que la modernidad debe ser comprendida como una «noche sagrada», es decir, como la época en que la relación con lo divino no se ha roto, pero donde es relación con la ausencia y no ya más con la presencia de los dioses ${ }^{32}$. Heidegger cita, para apoyarse, el poema «La noche», que dice el «tormento infinito» (unendliche Qual) de lo que atraviesa la noche espiritual y que accede así al cumplimiento del dolor por el cual solo la conquista del cielo y de Dios, del que habla también el poema, se ha vuelto posible, a través de lo que Trakl llama Geduld, aguante o paciencia. Se comprende entonces por qué Heidegger ha insistido en el

31 Ibid., p. 69. Beaufret traduce aquí de manera poco clara das Versammelnde por «lo que aparece» [«ce qui appareille»] en el sentido de lo que pone por igual [paire].

32 Cf. en particular Chemins qui ne mènent nulle part, op. cit., p. 327. 
hecho de que Elis, el joven muerto, no debe ser identificado con Trakl mismo, con el poeta: pues el que se vuelve poeta es primero el que escucha y sigue lo extraño, es el amigo del cual hablaba el poema «A un joven muerto» y el hermano, que es asunto en los poemas de Trakl.

Ahora se ha vuelto posible, según Heidegger, determinar la palabra propia de la poesía de Trakl33. Responde al ser en camino de lo extraño, que conduce lejos de la especie degenerada y hacia el mañana por venir de la especie ingenerada. Tal palabra, que tiene su paraje en la separación, responde al retorno a él, en la serenidad de la infancia, del hombre de la especie ingenerada. Es pues una palabra de la transición, del Übergang, que va del declinio, en el sentido de la decadencia, al declinio, en el sentido del acceso a lo espiritual. Aquí Heidegger cita, para apoyarse, un verso de Trakl que en un poema en prosa intitulado «Revelación y declinio» (Offenbarung und Untergang) canta «la belleza de una especie que retorna a ella» (die Schöhnheit eines heimkehrenden Geschlechts ${ }^{34}$ ). La palabra poética de Trakl habla así, a la vez, de lo que abandona y de ese verso que ella anticipa, es, pues, necesariamente ambigua (mehrdeutig). Heidegger insiste en la ambigüedad de las palabras fundamentales de Trakl, tales como declinio, noche, muerte, etc. Hay, pues, una pluralidad de sentido en el interior mismo de la poesía de Trakl. Y esta ambigüedad del decir poético de Trakl debe ser ella misma considerada como la otra cara de lo que no puede ser dicho, del Gedicht que sigue estando no-dicho, y es por eso que Heidegger habla de una ambigüedad, ella misma ambigua, de la poesía de Trakl. Pues ella no proviene de la indeterminación de un decir poético tanteante, como es el caso para tantos otros poetas, sino, al contrario, del rigor único en su género de la palabra de Trakl, de la que Heidegger no titubea en decir que le arrastra «infinitamente» en la exactitud técnica de los conceptos científicos. Se encuentra aquí la oposición que establecía Husserl entre la exactitud propia de las ciencias de la naturaleza y el rigor propio de la filosofía, pero aquí la palabra Strenge es aplicada por Heidegger a la poesía y relacionada con lo que él llamaba el Grundton, el tono fundamental del que proviene en unisón la pluralidad de los poemas y la ambigüedad de las palabras y lo que constituye, en su ensamblaje, el paraje de la poesía de Trakl.

Es la pregunta de la plurivocidad de la palabra de Trakl lo que conduce a la de su relación con el cristianismo. Heidegger no niega que Trakl haya utilizado un vocabulario de origen bíblico en sus poemas (transfiguración, maldición y, sobre todo, el término «geistlich», de connotación religiosa, que prefiere al de geistig, de connotación más metafísica). Y posiblemente Trakl ha sido marcado por el cristianismo, aunque cierta ambigüedad subsiste también en eso, ya que, de padre protestante y de madre católica, no parece que haya sabido bien, él mismo, a qué confe-

33 Ibid., p. 75.

34 Ibid., p. 76. 
sión pertenecía. Para Heidegger, la relación de Trakl con el cristianismo no puede ser juzgada más que a partir del momento en que el paraje de su poesía ha sido definido y no previamente a esta. Lo que implica posiblemente, como es ya el caso para Hölderlin, que se opere así un redescubrimiento del cristianismo menos como doctrina que como modo de existencia. Es por eso que Heidegger señala que los conceptos de la teología no pueden, en ningún caso, ser comprendidos como puntos de partida de esta discusión. Heidegger duda, por otra parte, de la actitud verdaderamente cristiana de Trakl, quien en sus dos últimos poemas no invoca ni al Cristo ni a Dios, sino «la sombra vacilante de su hermana» y llama a la eternidad «onda glacial». Porque para Heidegger Trakl, igualmente que Hölderlin, es el poeta de la retirada de lo divino, y no de la revelación cristiana y, como Nietzsche, está en busca de un porvenir que dar al hombre, antes que de la salvación eterna de aquel.

Queda una última cuestión que Heidegger aborda en la tercera y última parte de la conferencia, la de la relación de la poesía de Trakl con Occidente, el país de la noche. Porque el verdadero nombre del paraje en que se mantiene puede ser precisamente llamado Abendland, lo que remite, según Heidegger, a algo más antiguo que el Occidente platónico-cristiano y europeo. Tal Occidente no está en absoluto en decadencia, sigue estando, al contrario, en espera de sus habitantes, en tanto que país de la noche espiritual y de la retirada de lo divino, donde, como en la obra de Hölderlin, la relación con das Heilige, lo indemne, es más fuerte cuando este se retira que cuando este se da a ver en la figura de la divinidad. La retirada de lo divino no es, pues, en absoluto, decadencia y la época de la muerte de dios, para retomar una expresión de Nietzsche, no es en absoluto para Heidegger la de la desaparición de la dimensión azurea [azuréenne] de lo sagrado, sino, al contrario, la mañana del nacimiento de una nueva forma de hombres. Heidegger hace aquí alusión a los dos poemas de Trakl que hablan de Occidente, en particular el que es intitulado «Canto occidental» (Abendländisches Lied) donde, luego de estar pleno de las horas amargas del declinio, Trakl evoca a los amantes que, radiantes, levantan los párpados, luego, después de un signo de puntuación inatendido, dos puntos, escribe simplemente estas dos palabras: «Una especie» (Ein Geschlecht) señalando el ein. Es en esas dos simples palabras que Heidegger descubre el tono fundamental de la poesía de Trakl, pues la unidad de esa especie proviene de la matriz de los que, al separarse, han ensamblado la disensión de las especies en la suavidad de un doble pliegue. Pero aquí, precisa Heidegger, uno no quiere decir «uno en el lugar de dos», uno no debe ser comprendido en el sentido de uniformidad y no remite a ningún hecho biológico: ni al nivel de las razas ni al nivel de los sexos, no se trata de instalar una indiferenciación. Hace falta entender la palabra «Geschlecht» a partir de la poesía de Trakl, a partir de su canto, que es canto del declinio. Es por eso que esa palabra conserva la pluralidad de sus sentidos y designa tanto a la raza histórica del hombre, por oposición al orden de lo viviente, como a las especies y las familias al inte- 
rior de la humanidad, y como a los sexos. Se trata de una unidad que proviene de un retorno a la infancia, de una salida de la discordia, que permite vivir serenamente la pluralidad.

Heidegger termina su conferencia afirmando que nuestro pensamiento sigue siendo demasiado corto y nuestro oído sordo cuando vemos en Trakl un poeta de la decadencia y cuando le juzgamos «extraño a la historia». Su poesía no necesita de sujetos históricos porque habla del proceso histórico mismo, del destino reservado a la especie humana y, añade Heidegger, así la salva (rettet). En una conferencia datada del mismo año, 1953, Heidegger insiste en el hecho de que esa palabra significa originalmente «hacer aparecer», la salvación debe ser comprendida como el hecho de conducir algo a su ser ${ }^{35}$. ¿Es eso, pregunta, aún un sueño romántico que sigue estando a la distancia de la tecnicidad y de la economía del mundo moderno? O bien ¿es eso, al contrario, el claro saber del demente, del que no se deja encerrar en lo actual, que despliega la dimensión de un porvenir que no es solamente la prolongación del presente y seguiría estando así desprovisto de todo destino capaz de concernir al hombre en el origen mismo de su ser? El paraje de la poesía de Trakl es, pues, el país de la tarde, una tierra espiritual: en tanto que tal se opone tanto al Occidente metafísico-cristiano como a la Europa económico-técnica, tanto al pasado como al presente. Este Occidente, al que nos llama Trakl, es el país de los ingenerados, un Occidente aún en latencia (verborgen). Trakl es, así, a los ojos de Heidegger, el poeta de tal Occidente por venir.

Traducción de Gerardo Córdoba Ospina

35 Cf. «La question de la technique », in Essais et conférences, op. cit., p. 38. Ver igualmente p. 177. 